\title{
AUTOMAÇÃO DOS OPERADORES DE AGREGAÇÃO E DESLOCAMENTO PARA GENERALIZAÇÃO CARTOGRÁFICA NA REPRESENTAÇÃO DE REDES SOCIAIS
}

\author{
Automation of Aggregation and Displacement Operators for Cartographic \\ Generalization in Social Networks Representation \\ RENAN MARTINS POMBO \\ LUCIENE STAMATO DELAZARI \\ Universidade Federal do Paraná \\ Programa de Pós-graduação em Ciências Geodésicas \\ Centro Politécnico - J. das Américas \\ CEP: 81531-990 - Curitiba - PR - Brasil \\ renanpombo@ufpr.br; luciene@ufpr.br
}

\begin{abstract}
RESUMO
A generalização cartográfica sempre teve um caráter subjetivo, o que implica que mapas de mesma escala derivados de um mesmo mapa fonte, por diferentes cartógrafos, resultem em diferentes representações. Além disso, com a evolução da informática surgiu a necessidade da padronização deste processo para que os produtos cartográficos gerados fossem sempre os mesmos. Nesta pesquisa aborda-se a aplicação da generalização na representação de redes sociais de assistência social. Os nós desta rede são os atores sociais - indivíduos, grupos ou instituições - que atuam em uma região e as ligações existentes entre os mesmos são os arcos, sendo que estas ligações não são físicas. $\mathrm{O}$ foco do estudo é a automação dos operadores geométricos de agregação e deslocamento agindo sobre as feições pontuais, que são os atores sociais. Quando há sobreposição entre os atores sociais, os que possuem mesma classificação são agregados gerando um novo símbolo. Já o deslocamento é utilizado para resolver a sobreposição entre atores sociais de classes diferentes. Para tanto, foi desenvolvido um programa para a execução da generalização cujos resultados são apresentados neste artigo.
\end{abstract}


Palavras-chave: Automação em Generalização Cartográfica; Agregação; Deslocamento; Redes Sociais.

\section{ABSTRACT}

The map generalization has always had subjective characteristic, which implies that the same scale maps derived from the same source map can result in different representations because these processes can be made by different cartographers. In addition, the evolution of computer technology needs a standardization of this process so that generated cartographic products will be always the same. This research deals with the application of generalization in the representation of social networks of social assistance. The nodes of this network are the social actors individuals, groups or institutions - working in a region and the linkages among them are the arches; these links are not physical. The focus of the study is the automation of the geometric operators aggregation and displacement acting on the point features, which are social actors. When there is an overlap between the social actors that have the same classification, they are aggregated generating a new symbol. But the displacement is used to solve the overlap between social actors from different classes. In order to do so, a program was developed to implement the generalization. The results are presented in this paper.

Keywords: Automation in Map Generalization; Aggregation; Displacement; Social Networks.

\section{INTRODUÇÃO}

Rede social é uma forma de representação dos relacionamentos afetivos ou profissionais entre si ou entre seus agrupamentos de interesses mútuos. Genericamente, as redes sociais são compreendidas como um conjunto de atores sociais (pessoas, grupos e instituições), chamados de nós, que se interligam quando há relações entre eles, e que integram um sistema social. O conjunto das relações dentro deste sistema pode ser representado por uma rede, por exemplo, por meio de um conjunto de pontos, total ou parcialmente, interligados (DELAZARI, SLUTER e KAUCHAKJE, 2007).

Representações georreferenciadas de Redes Sociais voltadas à assistência social já foram estudadas nos trabalhos de Marchis (2008) e Pombo (2009). Na pesquisa do primeiro trabalho, os resultados obtidos possibilitaram o aumento do conhecimento do analista social sobre a rede, através do uso dos mapas com a exploração das redes sob o aspecto geográfico.

A continuidade das pesquisas nessa área consiste na tentativa de automação dos operadores de generalização cartográfica utilizados para a representação de redes sociais. Pesquisas em automação de operadores de generalização estão sendo desenvolvidas em vários países como pode ser observado ao se verificar os trabalhos dos últimos congressos da Associação Internacional de Cartografia (ICA), nos quais se encontram pesquisas realizadas por Sester (2005), Burghardt (2009), Lee (2011), Steiniger (2013) e outros. 
O processo de generalização cartográfica, por apresentar uma grande componente de subjetividade, constitui-se como um dos mais complexos a ser documentado e implementado. A subjetividade do processo encontra-se na identificação e descrição de como realizar a generalização, pois depende da experiência, da intuição e do conhecimento da área a ser abstraída por parte do profissional responsável pelo processo, além da escala, objetivo do mapa e necessidades do usuário.

Neste artigo aborda-se, especificamente, o problema da automatização dos operadores de agregação e deslocamento aplicados a feições pontuais. Neste estudo de caso, com a diminuição da escala, os símbolos próximos começam a se sobrepor, o que provoca o congestionamento e a confusão na representação em regiões onde a densidade de pontos é maior. As decisões que devem ser formalizadas concernem a, primeiramente, qual operador utilizar diante da classificação dos símbolos localizados em regiões de dificuldade de representação. Após isso devem ser estabelecidos os parâmetros para a execução do operador escolhido como, por exemplo, o tamanho do símbolo resultante da agregação.

$\mathrm{Na}$ sequência do texto explana-se o conceito da análise de redes e sua aplicação nas ciências sociais em conjunto com a contribuição que a cartografia trouxe a esse ramo de pesquisa. Em seguida, aborda-se a generalização cartográfica e sua automatização. Estes dois temas são os pilares desta discussão, que visa verificar o que e como é alterado acerca do entendimento da representação inicial, após os procedimentos de generalização automatizada dos operadores de agregação e deslocamento. Faz-se, também, uma avaliação dos algoritmos implementados e é realizada uma análise dos resultados, ilustrando-se inclusive resultados parciais, em que se verifica quando começam a surgir os problemas de representação e debatida a solução usada para cada conflito. Além de uma comparação entre as generalizações manual e automática. Por fim, o artigo é finalizado com uma discussão acerca do trabalho com relação a suas limitações e recomendações nos aspectos em que se pode avançar.

\section{ANÁLISE DE REDES SOCIAIS}

O termo rede é usado em várias áreas do conhecimento, com diversas acepções e diferentes aplicações. Há conceitos simples para rede como, por exemplo, um entrelaçado de tecido, além de conceitos complexos como a ligação entre computadores de todo o mundo. Segundo Loiola e Moura (1997), identificam-se diversas definições de rede, partindo da noção de entrelaçamento de fios e formação da malha e sua analogia com as concepções nas engenharias, nas ciências organizacionais e sociais, passando por outros sentidos, que incluem armadilha, instrumento de proteção, instrumento de sustentação e marco divisório entre concorrentes. O conceito também representa a ideia de fluxo e de circulação, tais como redes de comunicação, de transportes.

As análises de redes enfatizam as relações entre os atores, o que significa que estes normalmente não são amostrados independentemente, como no caso de outros 
tipos de dados convencionais que focalizam nos atores e nos atributos. $\mathrm{O}$ estudo das redes complexas foi iniciado pelas ciências exatas e, em seguida, utilizado pela sociologia, numa perspectiva de análise estrutural das redes sociais (TOMAEL e MARTELETO, 2006).

As redes sociais com o auxílio da cartografia ganharam suporte para ampliar o conhecimento de seus analistas através de uma componente espacial originada do georreferenciamento dos atores sociais e seus relacionamentos (DELAZARI et al, 2007).

A visualização cartográfica associada à análise de redes sociais aumenta o conhecimento dos analistas. Isto porque com a espacialização das informações, os profissionais têm os atributos espaciais dos componentes da rede para serem observados. A partir daí podem verificar padrões quanto aos aspectos socioeconômicos, culturais e históricos. No domínio privado o usuário pode explorar se há presença de atores sociais em regiões mais carentes de um determinado serviço e com isto obter conclusões a respeito do fenômeno estudado. $\mathrm{O}$ analista interpreta estas informações e as apresenta ao domínio público de maneira a mostrar as características mais relevantes a respeito da rede social abordada.

A análise de redes em SIG é fundamentada em teoria dos grafos e topologia. Uma dificuldade existente na representação cartográfica destes grafos é o fato de que alguns de seus elementos não são condizentes com suas características espaciais, como as conexões, por exemplo, mas com seus atributos topológicos. Isto significa que propriedades como conectividade, adjacência e incidência não devem se alterar devido a um processo de representação cartográfica (CURTIN, 2007). Estas características não apresentam uma referência espacial. A conectividade, por exemplo, pode ser representada tanto por uma curva como por um segmento de reta que não altera o seu significado. Por isso às vezes pode ocorrer de uma representação automática não ser tão eficiente como se esperava na representação de uma rede. Cabe ao cartógrafo decidir pela melhor forma de representação, minimizar os problemas e justificá-los.

\section{GENERALIZAÇÃO CARTOGRÁFICA}

A generalização cartográfica é entendida como um processo de ajustamento de conteúdo e gráfico, com a finalidade de melhorar o uso de dados geográficos a um nível mais elevado da percepção visual de entidades espaciais tal como das suas relações. Assim, pode-se considerar a generalização como uma forma de filtro. A generalização é um procedimento dependente da escala, mais precisamente da razão entre as escalas envolvidas, escala do mapa fonte e mapa resultante, e principalmente dos objetos representados. Quanto maior for a razão entre as escalas, maior a necessidade de generalização de objetos representados no mapa (LOPES, 2005).

Os dois tipos principais de generalização são, segundo Jones (2003), generalização semântica - baseada na escolha inicial da informação relevante a ser

Bol. Ciênc. Geod., sec. Artigos, Curitiba, v. 20, nº 3, p.669-682, jul-set, 2014. 
apresentada no mapa; e generalização geométrica - baseada na manipulação de características gráficas de objetos representados no mapa.

A necessidade de generalizar surge de fatores objetivos e subjetivos. Os objetivos são a escala e os requisitos gráficos. Os subjetivos são a característica e a importância das feições. A escala e a densidade de informação condicionam o espaço disponível para a representação. Os requisitos gráficos têm a ver com a legibilidade do que se está representando. Devido a sua importância algumas feições devem ser exageradas. E em outros casos as características das feições não devem ser generalizadas (FIRKOWSKI, 2002).

A generalização cartográfica no meio digital é realizada com base em operações de transformações estatísticas e operações geométricas. Mcmaster e Shea (1992) propõem um conceito de generalização adequado à cartografia digital: "a generalização digital pode ser definida como o processo de derivar um conjunto de dados cartográficos simbolicamente ou digitalmente codificados pela aplicação de transformações espaciais e de atributos a uma fonte de dados". Logo, segundo Firkowski (2002), pode-se dizer que na cartografia convencional a generalização é realizada pela manipulação de imagens gráficas (pontos, linhas e áreas), e na cartografia digital a generalização é realizada pela "manipulação computacional" no arquivo da representação digital de feições cartográficas.

Com a evolução em ciência da computação houve uma aceleração no desenvolvimento do mapeamento e da cartografia além de outras ciências. A cartografia digital preenche o espaço antes ocupado pelo mapeamento clássico, ou seja, técnicas clássicas foram substituídas por técnicas digitais de produção de mapas. Além do uso de mapas em papel, a demanda por mapas digitais e conjunto de dados geográficos vem em um constante crescimento. Paralelamente a estes desenvolvimentos, as agências nacionais de mapeamento começam a valorizar a importância da coleta dos dados de forma a completar os seus conjuntos de informações digitais sobre seus territórios e investem nessa área. Com as bases cartográficas digitais surgem dois novos caminhos a serem explorados: a atualização das bases e a produção de mapas em diferentes escalas oriundos do conjunto de dados, o que concerne à generalização cartográfica (HARDY et al, 2003).

A generalização é uma importante questão da cartografia e a automação do seu processo é de extrema importância devido ao aumento do fluxo de produção e na padronização dos resultados derivados. Os operadores de generalização são meios para tentar descrever a natureza da generalização automática. Esses foram definidos num esforço de emular as técnicas de generalização manual baseadas em técnicas matemáticas (MACMASTER e SHEA, 1992). Os operadores consistem em transformações espaciais como simplificação, suavização, agregação, amalgamação, fusão, colapso, seleção, refinamento, tipificação, exagero, realce e deslocamento; e em transformações semânticas como classificação e simbolização (KILPELAINEN, 1999).

A seleção de métodos de generalização, algoritmos, operadores e parâmetros é extremamente dependente da fonte e do uso dos dados e suas especificações. 
Consequentemente a qualidade, a acurácia e o conteúdo dos dados fonte, utilizados como entrada, são importantes fatores na generalização. É primordial que estes dados passem por uma padronização para eliminação de erros e reforço no seu conteúdo. Também é necessário que o conjunto de dados esteja apresentado em banco de dados para eliminar redundância no conteúdo (ASLAN et al, 2004).

\section{METODOLOGIA}

O presente trabalho apresenta a automação de dois operadores de generalização cartográfica existentes, descrevendo-se os procedimentos necessários para automatizar os operadores agregação e deslocamento aplicados na redução de escala de representações de redes sociais.

Foram utilizados os mesmo dados das pesquisas de Marchis (2008) e Pombo (2009) que se referem aos atores sociais das redes sociais que garantem o direito à assistência social na cidade de Curitiba. Os dados foram coletados através de pesquisas em sítios de busca na internet concernentes aos temas: saúde, trabalho, habitação, alimentação, educação e assistência social.

Os mapas foram produzidos com o programa ArcGIS, que permite a variação da escala de representação e a ocultação de determinados tipos de feições no mapa. Além de permitir a variação da simbologia. Para a organização dos dados em tabelas se utilizou o Microsoft Excel, que também foi usado para a conversão de formatos dos arquivos, por exemplo, de dbf para csv e deste para xls.

O computador utilizado para os experimentos é um Athlon Dual Core que trabalha com a plataforma Windows. E ao considerar estas características desenvolveu-se o programa de generalização usando a linguagem C Sharp e os aplicativos no Microsoft Visual Studio.

Estabeleceu-se como meta alcançar com o processo automatizado resultados semelhantes aos da generalização manual executadas no trabalho de Pombo (2009). Em ambos os trabalhos aplicou-se a agregação aos símbolos pontuais sobrepostos e de mesma classificação - com a mesma simbologia. Caso contrário, na ocorrência de conflito entre símbolos diferentes será utilizado o operador de deslocamento.

Para realizar a automatização, foi desenvolvido um algoritmo na linguagem C Sharp que combina a aplicação dos dois tipos de operador abordados pela pesquisa. O programa foi desenvolvido para plataforma Windows (Figura 1) e funciona independente do ArcGIS, programa utilizado na pesquisa para a representação cartográfica digital das redes sociais.

A primeira etapa consiste na adequação dos dados. Para isso, o usuário deve abrir o conjunto de dados a ser generalizado, que está armazenado em arquivos com extensão shp, por meio de um programa SIG. O arquivo shapefile deve ser exportado para um arquivo com extensão compatível com programas editor de planilhas, no caso, o Microsoft Excel. Com este programa o arquivo deve ser salvo com a extensão csv (separação de colunas por vírgulas). Este último formato é o utilizado para os dados de entrada no programa desenvolvido. 
Figura 1 - Interface do programa de generalização.

Fonte: Pombo (2009).

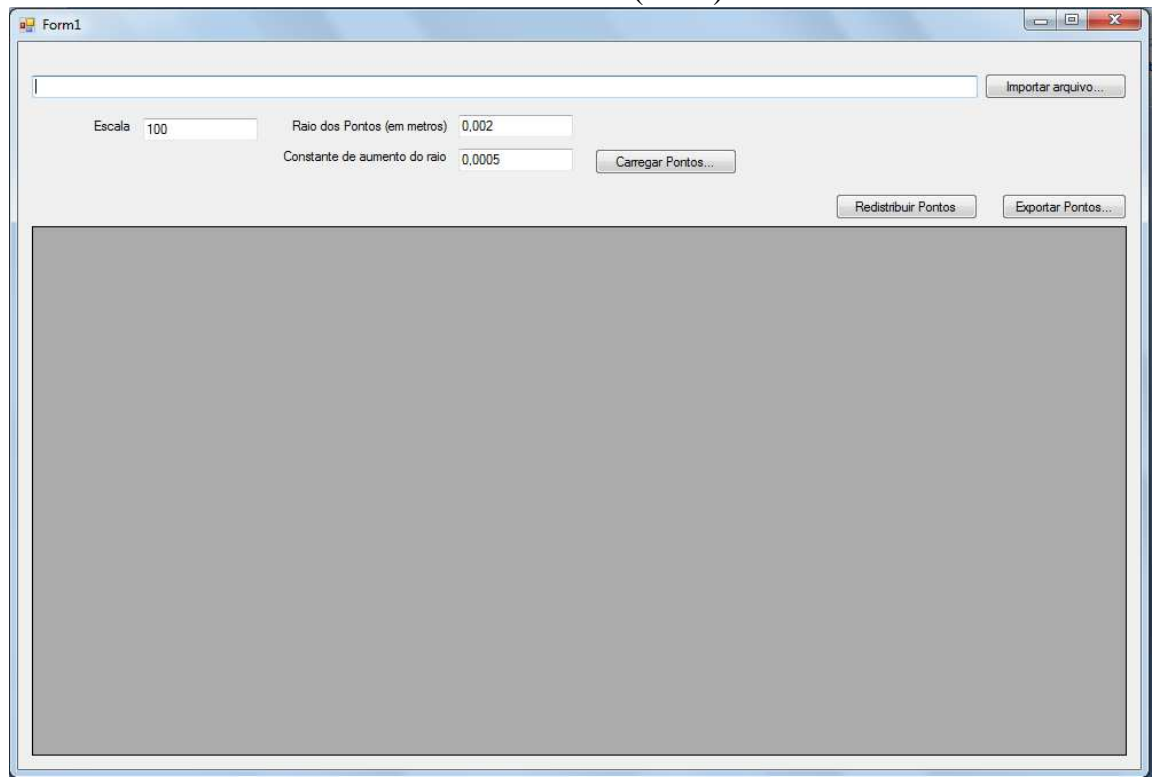

Após a adequação dos dados, pode-se executar o programa de automatização. No botão "Importar arquivo" (no canto superior direito) seleciona-se o arquivo com extensão csv. Na janela escala configura-se o valor do denominador da escala. Há duas lacunas concernentes ao raio dos símbolos. No espaço designado para o "Raio dos Pontos", o usuário deve preencher com o valor mínimo do raio que o menor símbolo na escala original pode assumir. Optou-se por representar todos os pontos por círculos para facilitar a implementação do algoritmo. E na janela de constante do raio, arbitra-se o valor de quanto o raio deve aumentar para a representação de símbolos agregados.

Após inserir os dados de entrada, deve-se clicar no botão "Carregar Pontos", a partir do qual o programa faz a leitura do arquivo de extensão csv e apresenta na tela a tabela de atributos do conjunto de dados. Para realizar o processo de generalização automática clica-se no botão "Redistribuir Pontos", e então é gerado um novo arquivo, que deverá ser exportado e salvo num formato de entrada para o ARCGIS, a extensão xls, por exemplo. Para visualizar os resultados deve-se importar este arquivo no SIG, classificar os dados e aplicar a simbologia.

Para entender o funcionamento do algoritmo mais detalhadamente, primeiramente devem ser fornecidas as variáveis: escala, raio e constante de aumento do raio. A partir do arquivo com as coordenadas dos pontos (nós da rede), o programa calcula e armazena as distâncias entre todos os pontos da rede. Para 
realizar o procedimento de agregação, o programa determina qual é a distância mínima para evitar o conflito na simbologia. Esta distância é definida a partir do produto entre o raio do símbolo na representação e o valor da escala. Em seguida o algoritmo verifica quais as distâncias são menores do que o valor mínimo permitido e armazena os pontos envolvidos.

Em seguida, verifica-se a classificação dos pontos. Caso os pontos tenham a mesma classificação, são agregados num único cujas coordenadas são obtidas através da média entre as coordenadas dos pontos do qual se originou. $\mathrm{O}$ raio deste novo símbolo é determinado em função da quantidade de símbolos agregados.

Caso os símbolos sejam diferentes entre si, o programa escolhe randomicamente um dos pontos envolvidos e suas coordenadas são somadas ou subtraídas do valor do raio multiplicado pela escala até que não haja mais sobreposição entre os símbolos. Caso este deslocamento provoque novos conflitos, o procedimento recomeça, porém com o ponto que não havia sido sorteado primeiramente. Se ainda houver conflito, move-se o terceiro ponto que impede a separação dos símbolos e assim por diante até que não ocorram mais congestionamentos. Por fim, é organizado um novo arquivo com os pontos generalizados.

Este novo arquivo é criado no formato csv, portanto deve ser aberto, no Excel, por exemplo, e salvo em um formato reconhecível pelo ArcGIS, para que este consiga representar os dados no mapa.

\section{DISCUSSÃO DOS RESULTADOS}

As Figuras apresentadas nesta seção referem-se aos testes realizados a partir de dados da rede social de saúde de Curitiba na escala de 1:75.000. O objetivo é a produção de representações na escala de 1:250.000, a qual permite visualização de toda a base cartográfica do município de Curitiba em monitores de 15" . Porém foram feitos testes com escalas intermediárias para que fosse percebido quando e como ocorrem os problemas de representação. A Figura 2 mostra a representação na escala original de parte da rede social de saúde, mais especificamente, na região central (Regional Matriz), onde há a maior concentração de atores sociais com raio mínimo de $1 \mathrm{~mm}$.

As 3 escalas intermediárias adotadas nos testes foram 1:100.000, 1:150.000, 1:200.000. Na escala de 1:100.000 não houve alterações na posição dos atores, por não ocorrer problemas de representação. As sobreposições começaram a partir da escala de 1:150.000.

Os novos símbolos apesar de serem representados com círculos de raio $1 \mathrm{~mm}$ maior, ou seja, com diâmetro de $4 \mathrm{~mm}$, causam problemas de representação ao nível de divisão por bairros, pois estes extrapolam os limites e acabam ocupando regiões em mais de um bairro da cidade. Porém com a divisão por regionais (Figura 2), esse tipo de conflito não existe. 
Figura 2 - Dados originais na escala 1:75.000 com divisão por regionais (imagem reduzida).

Fonte: Pombo 2009.

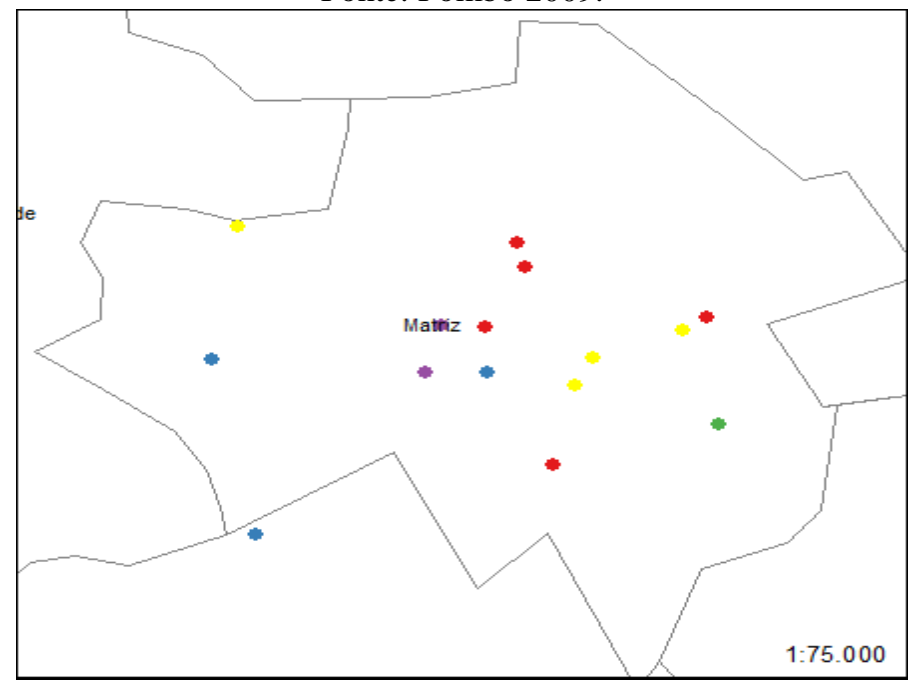

Com a diminuição da escala os congestionamentos entre os símbolos aumentam em quantidade como pode se notar na Figura 3 que está na escala de $1: 250.000$.

Figura 3 - Dados não generalizados para a escala 1:250.000 (imagem reduzida). Fonte: Pombo 2009.

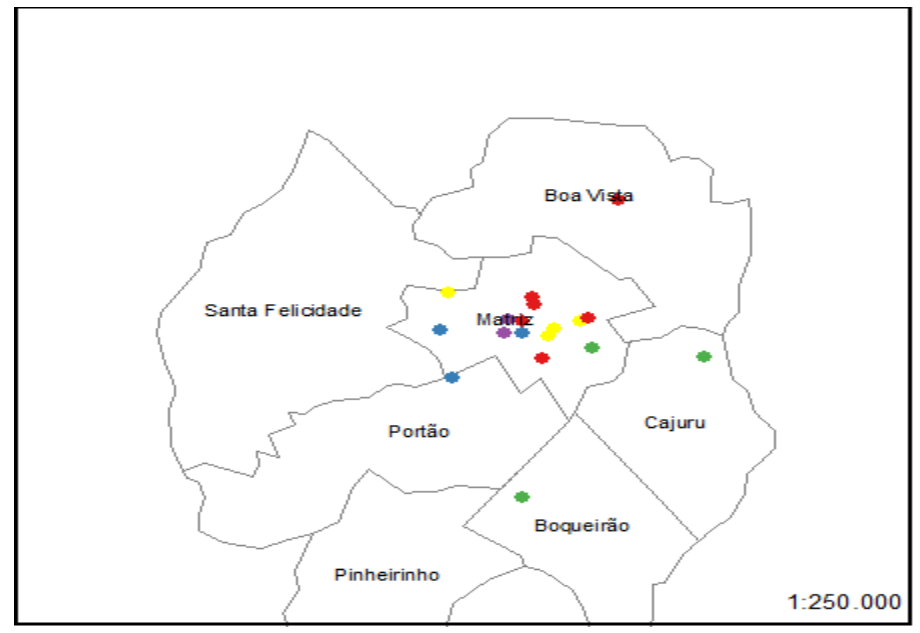

Bol. Ciênc. Geod., sec. Artigos, Curitiba, v. 20, nº 3, p.669-682, jul-set, 2014. 
O resultado do programa de generalização evidencia que novos deslocamentos foram executados e aplicados aos círculos ( 2 roxos, 1 vermelho e 1 azul), no centro da ilustração. A representação generalizada pode ser vista na Figura 4. Os atores que antes pareciam representar os 4 vértices de um retângulo, foram reconfigurados formando uma linha em diagonal.

Na Figura 5 é apresentado o resultado obtido pela generalização manual feita no trabalho de POMBO (2009). Este executou o processo também evitando sobreposições com os topônimos e visou um maior espalhamento entre os símbolos para a adição de toponímia aos atores sociais. O autor se preocupou com a orientação relativa das feições pontuais entre si e pode-se verificar na Figura 4 que esta foi mantida na maioria das situações. A maior diferença entre as duas generalizações está relacionada aos os círculos em roxo. $\mathrm{Na}$ generalização automática houve um deslocamento entre eles, pois havia outros símbolos próximos, o que preservou as feições. Já na manual houve agregação entre estes símbolos com o intuito de manter a orientação relativa entre eles.

Figura 4 - Dados generalizados para a escala 1:250.000 (imagem reduzida).

Fonte: Pombo 2009.

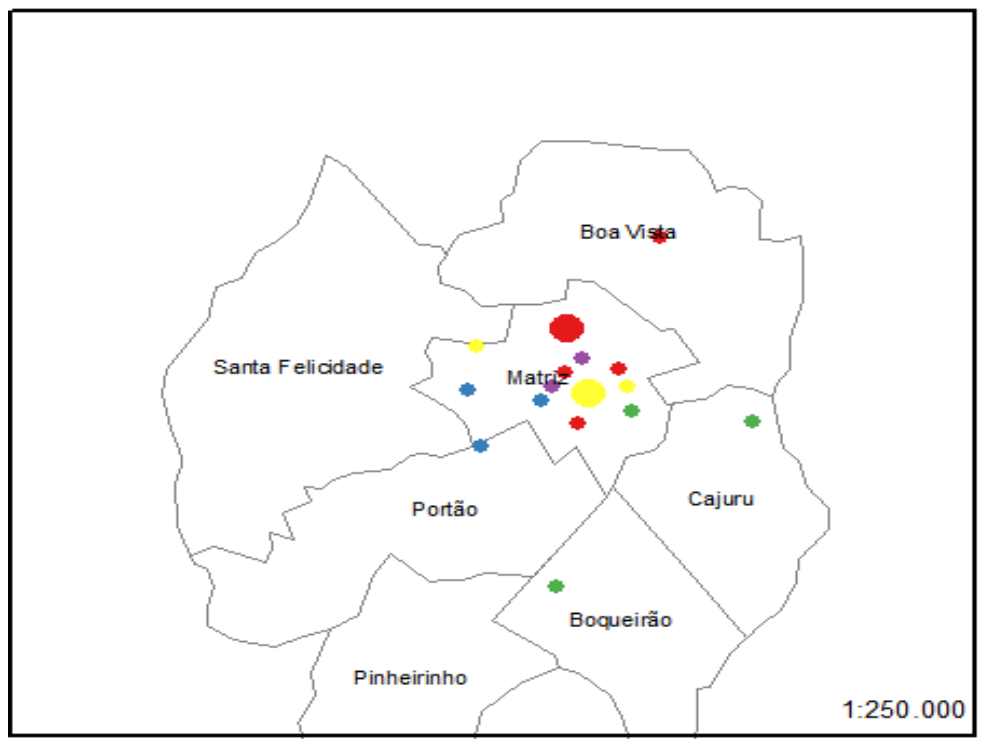

O algoritmo desenvolvido na linguagem $\mathrm{C}$ sharp foi eficiente para a generalização dos nós da rede social. Porém, este deve ser melhorado visando uma maior integração entre os dados da rede e a base cartográfica utilizadas. Foram executados testes com vários tamanhos mínimos para os símbolos pontuais, parametrizado através do raio, pois se tratavam de círculos. 
Os símbolos agregados, aqueles formados por dois ou mais atores sociais, foram representados em tamanho maior, por isso, muitas vezes, o programa deve realizar novos deslocamentos e agregações para que todos os nós se rearranjem. Nos testes onde foi arbitrado um tamanho mínimo de símbolo com raio de $4 \mathrm{~mm}$ ou mais, na escala final os nós aparecem situados fora dos limites municipais, ou seja, a configuração da rede é modificada em relação às suas referências espaciais.

Figura 5 - Dados generalizados manualmente para a escala 1:250.000 (imagem reduzida).

Fonte: Pombo 2009.

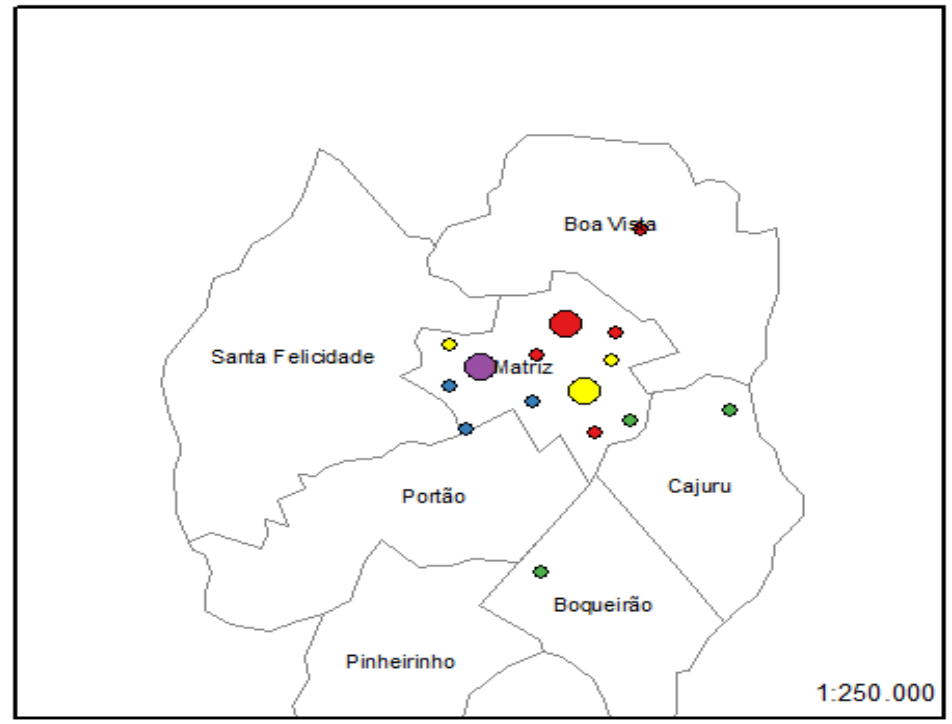

Não há uma certeza de solução única quando o operador de deslocamento é aplicado, devido a seu caráter randômico, nem sempre as generalizações resultantes apresentam os mesmos resultados. Isto porque a cada nova utilização do programa, o algoritmo sorteia qual ator será deslocado e a sua direção. No entanto para efeitos de análise, as conclusões são independentes a pequenas movimentações, desde que não haja mudanças bruscas na referência espacial. Em comparação com a generalização manual os resultados apresentaram-se bastante semelhantes entre si.

\section{CONCLUSÃO}

Neste estudo de caso foi desenvolvido um programa, que através da leitura de um arquivo com coordenadas, detecta os problemas de representação e regiões com congestionamento de símbolos, que ocorrem com a diminuição da escala. Estes conflitos de representação, uma vez encontrados, passam por um processo de análise onde se verifica qual deve ser o operador aplicado ao caso. Nas situações em 
que os símbolos sobrepostos apresentam a mesma classificação, estes são agregados, caso contrário, os símbolos são afastados com a aplicação do operador deslocamento para que não entrem em colapso na representação.

Para a melhoria do programa, recomenda-se a implementação de restrições quanto ao posicionamento geográfico dos símbolos como, por exemplo, criar barreiras para que os pontos deslocados não ultrapassarem determinados limites de modo a preservar a referência espacial.

É necessário restringir o tamanho de símbolos que fiquem maiores do que feições de área da representação, para que um símbolo pontual não oculte um bairro inteiro. A redução de etapas randômicas também é importante, como por exemplo, priorizar a manutenção da posição de símbolos agregados, por serem mais expressivos, e mover símbolos que representem apenas um ator social.

Para a continuidade da pesquisa deve-se também estudar a generalização para os fenômenos lineares das redes, pois as relações são parte importante para o entendimento da rede social. Não só a rede, como a base cartográfica deve passar por processos de generalização. Neste caso, podem ser aplicados métodos de generalização cartográfica já desenvolvidos por outros pesquisadores.

Além disso, tornar o programa mais genérico aumentará a sua difusão para cartografia e para o SIG, o que deixará de restringir seu uso a determinados tipos de representação. Logo, a intenção é de torná-lo apto para a generalização de todos os tipos de representação em rede.

\section{AGRADECIMENTOS}

Os agradecimentos desta pesquisa vão para o grupo de pesquisa em visualização cartográfica da Universidade Federal do Paraná pelas importantes colaborações. E para o Curso de Pós-graduação em Ciências Geodésicas da mesma universidade pelo suporte oferecido para o desenvolvimento do trabalho.

\section{REFERÊNCIAS BIBLIOGRÁFICAS}

BURROUGH, P. A.; Principles of Geographical Information Systems, Oxford University Press - New York, 1998, p. 27-59.

CURTIN, K. M. Network Analysis in Geographic Information - Science: Review, Assesment, and Projections, Cartography and Geographic Informations Science, vol. 34, $\mathrm{n}^{\circ}$ 2, 2007, p 103-111.

DELAZARI, L. Modelagem e implementação de um Atlas eletrônico interativo utilizando métodos de visualização cartográfica. Tese apresentada à Escola Politécnica da Universidade de São Paulo. 2004.

DELAZARI, L., PENNA, M., KAUCHAKJE, S. Sistema de informação geográfica como suporte à gestão da rede e política social. Disponível em: http://www.geogra.uah.es/inicio/web_11_confibsig/PONENCIAS/2-052Delazari-Penna-Kauchakje.pdf $>$. Acesso em: dez 2007.

DENT, B.D. Principles of Thematic Map Design. Reading, Massachusetts,Estados Unidos: Addison-Wesley, 1985. 387p. 
FIRKOWSKI, H. Generalização Cartográfica de Grades Retangulares Regulares Baseada na Teoria Matemática da Comunicação. Curitiba, 2002.Tese (Doutorado em Ciências Geodésicas) - Universidade Federal do Paraná.

HANNEMAN, R. Computer-Assisted Theory Building: Modeling Dynamic Social Systems. Sociology Departament. 1988. < http://faculty.ucr.edu/ hanneman/ >. Acesso em: dez 2007.

HARDY, P. Map Production From An Active Object Database, Using Dynamic Representation and Automated Generalization. Laser-Scan Ltd, Science Park, Milton Road, Cambridge, CB4 4FY, UK, 1999.

HOROWITZ, E.; SAHNI, S. Fundamentos de Estruturas de Dados. Editora campus. Rio de Janeiro. 1984.

INTERNATIONAL CARTOGRAPHIC ASSOCIATION (ICA) - Commission on Visualization. Commission Overview. [online]. Disponível em: www.geog. psu.edu/ica/icavis/ICAvis_overview(1). html>. 2004.

JOÃO, E.M. Causes and Consequences of Map Generalization. 1. ed. Great Britain: Department of Geography and Environment, Taylor and Francis, London School of Economics, 1998, 266p.

JONES, C. and van der POORTEN, P., Customisable Line Generalization using Delaunay Triangulation. University of Glamorgan, 2003.

KAUCHAKJE, S. et al. Rede sócio-técnica de proteção social: o direito à habitação em Curitiba. 2006.

KEATES, J.S. Cartographic Design and Production. 2. ed. Essex: Logman Scientific \& Technical, New York, 1989.

LOPES, J. Generalização Cartográfica. Dissertação apresentada a Universidade de Lisboa. 2005.

MARCHIS, C. Proposição de projeto cartográfico para representação de redes sociais. Curitiba, 2008. Dissertação de Mestrado - Universidade Federal do Paraná.

MARTELETO, R. M. Análise de redes sociais - aplicação nos estudos de transferência da informação. Ciência da Informação, jan./abr. 2001. $<$ http://www.scielo.br/scielo.php?script=scji_arttext\&pid=S010019652001000100009\&Ing=pt\&nrm=isso> Acesso em 24 jan 2008.

MATHEUS, R. F.; SILVA, A. B. O. Análise de rede social como método para a ciência da informação. Revista de Ciência da Informação, vol. 7, n. 2, 2006. <http://www.netic.com.br/redeci/images/stories/docs/ars.pdf> Acesso em: 25 mai 2008.

McMASTER, R.B. Conceptual Frameworks for Geographical Knowledge In: BUTTENFIELD, B.P.; McMASTER, R.B. Map Generalization. Avon: Logman Scientific \& Technical, 1991.

McMASTER, R.B.; SHEA, K.S. Generalization in Digital Cartography. 1.ed.Washington: Association of American Geographers, 1992. 133p. 
MINELLA, A. Tópicos especiais: Introdução à Análise de Redes Sociais. UFSC. Disponível em <http://www.sociologia.ufsc.br/programas/spo/spo3711b (20081).html> . Acesso em: abr 2008.

MONMONIER, M. How to lie with maps. 1.ed. Chicago: The University of Chicago, 1991. 176p.

MULLER, J. et al. Generalization: state of the art and issues. Geographisches Institut, Ruhr Universitat Bochum, Universitastraße 150, 44780. Bochum, Germany. 1991.

NALINI, V. Avaliação cartométrica da base cartográfica digital adequada à gestão urbana derivada por generalização cartográfica a partir da escala de origem 1:2000. Curitiba, 2008. Dissertação de Mestrado - Universidade Federal do Paraná.

PHILLIPS, D, T; ALBERTO G. Fundamentals of Network Analysis. Englewood Cliffs: Prentice Hall, Inc, 1981.

POMBO, R, M. Generalização Cartográfica Aplicada na Representação de Redes Sociais. Curitiba, 2009. Dissertação de Mestrado - Universidade Federal do Paraná.

ROBINSON, A. H. et al. Elements of cartography. 6 ed. [S.I.] John Wiley \& Sons, 1995.

SLOCUM, T.A. Thematic Cartography and Visualization. Estados Unidos: Prentice-Hall, 1999.

TOMAÉL, M. I.; MARTELETO, R. M. Redes Sociais: posições dos atores no fluxo da informação. Encontros Bibli., Florianópolis, n.esp., 1. sem. 2006.UCINET. Disponível em <http://www.analytictech.com/downloaduc6.htm>. Acesso em: nov 2007.

VIANNA, C.R.F. Generalização Cartográfica em Ambiente Digital Escala 1:250. 000 a partir de Dados Cartográficos Digitais na Escala 1:50.000. Rio de Janeiro, 1997. Dissertação (Mestrado em Engenharia Cartográfica) Departamento de Engenharia Cartográfica, Instituto Militar de Engenharia.

(Recebido em outubro de 2013. Aceito em maio de 2014). 